\title{
Evaluation of PERSIANN-CCS Rainfall Measurement Using the NAME Event Rain Gauge Network
}

\author{
YANG HONG* \\ Center for Hydrometeorology and Remote Sensing, Department of Civil and Environmental Engineering, University of California, \\ Irvine, Irvine, California \\ DAVID GochIS \\ National Center for Atmospheric Research, Boulder, Colorado \\ Jiang-Tao Cheng, Kuo-lin Hsu, and Soroosh Sorooshian \\ Center for Hydrometeorology and Remote Sensing, Department of Civil and Environmental Engineering, University of California, \\ Irvine, Irvine, California
}

(Manuscript received 15 March 2006, in final form 20 July 2006)

\begin{abstract}
Robust validation of the space-time structure of remotely sensed precipitation estimates is critical to improving their quality and confident application in water cycle-related research. In this work, the performance of the Precipitation Estimation from Remotely Sensed Information using Artificial Neural Networks-Cloud Classification System (PERSIANN-CCS) precipitation product is evaluated against warm season precipitation observations from the North American Monsoon Experiment (NAME) Event Rain Gauge Network (NERN) in the complex terrain region of northwestern Mexico. Analyses of hourly and daily precipitation estimates show that the PERSIANN-CCS captures well active and break periods in the early and mature phases of the monsoon season. While the PERSIANN-CCS generally captures the spatial distribution and timing of diurnal convective rainfall, elevation-dependent biases exist, which are characterized by an underestimate in the occurrence of light precipitation at high elevations and an overestimate in the occurrence of precipitation at low elevations. The elevation-dependent biases contribute to a 1-2-h phase shift of the diurnal cycle of precipitation at various elevation bands. For reasons yet to be determined, the PERSIANN-CCS significantly underestimated a few active periods of precipitation during the late or "senescent" phase of the monsoon. Despite these shortcomings, the continuous domain and relatively high spatial resolution of PERSIANN-CCS quantitative precipitation estimates (QPEs) provide useful characterization of precipitation space-time structures in the North American monsoon region of northwestern Mexico, which should prove useful for hydrological applications.
\end{abstract}

\section{Introduction}

Most locations of the world lack sufficient precipitation observing networks required for water resources management, climatological analysis, and natural haz-

\footnotetext{
* Current affiliation: Goddard Earth Science and Technology Center, Baltimore, and NASA Goddard Space Flight Center, Greenbelt, Maryland.
}

Corresponding author address: Dr. Yang Hong, NASA Goddard Space Flight Center, Mail Stop 613.1, Greenbelt, MD 20770. E-mail: yanghong@agnes.gsfc.nasa.gov ard mitigation. This feature is particularly true in complex terrain regions where human settlements and infrastructure are sparse. Yet even in well-populated regions with sophisticated infrastructure, simple pointbased measurements, using rain gauges, may not be sufficient for characterizing the spatial patterns of precipitating weather systems. The spatial distribution of gauge observing networks are also typically biased toward locations where people and infrastructure coexist (e.g., at lower elevations, near principal natural resources, along transportation corridors, near electricity and communications networks, etc.) and there is no guarantee that the positioning of these features permits

DOI: $10.1175 / J H M 574.1$

(C) 2007 American Meteorological Society 
adequate sampling of the spatial distribution of rainfall structures.

Advances in our understanding of global hydrometeorological processes will require detailed precipitation estimates on a broad range of time and space scales. Assimilation of precipitation information into global and regional models should produce more realistic simulations. On smaller scales, knowledge of surface rainfall will be useful for the improvement of land surface hydrology models. Satellite observations provide a critical contribution toward mapping global rainfall and its variability. Currently, precipitation estimates from orbiting platforms provide estimates of precipitation across multiple space and time scales. However, satellite-based estimates need to be validated against the best known estimates of precipitation coming from rain gauge or radar products.

The North American Monsoon Experiment (NAME) Event Rain Gauge Network (NERN) of Gochis et al. (2003, 2004) provides a rich opportunity for validating satellite-based precipitation estimates in a convectively dominated, complex terrain region. The North American monsoon (NAM) system is increasingly recognized as a dominant, modulating feature of the warm season climate over North America (Higgins et al. 2003, 2006). The onset of seasonal rains in southwestern North America is critical to the function and sustenance of ecosystems as well as supplying water resources for domestic and agricultural purposes. This fact is particularly true for the region encompassing the Sierra Madre Occidental (SMO) in western Mexico, which receive, on average, between $50 \%$ and $80 \%$ of their annual water resource from monsoon precipitation (Mosiño and Garcia 1974; Douglas et al. 1993; Gochis et al. 2006). However, the character (i.e., intensity and frequency structure) of monsoon precipitation events in the core monsoon region of the SMO varies greatly as a function of the diurnal cycle, terrain elevation, distance to principal moisture sources, and the influence of mesoscale and synoptic-scale transient weather systems (Carleton 1986; Berberry 2001; Douglas and Leal 2003; Gochis et al. 2004, 2007; Lang et al. 2007). The strong spatial and temporal variance in precipitation structures necessitates a rigorous evaluation of remotely sensed precipitation estimates in order to use these estimates with confidence.

In this paper, quantitative precipitation estimates (QPEs) from the multisatellite precipitation retrieval algorithm, Precipitation Estimation from Remotely Sensed Information using Artificial Neural NetworksCloud Classification System (PERSIANN-CCS; Hong et al. 2004), are validated against ground-based rain gauge observations from the NERN. PERSIANN-CCS has been evaluated for the continental United States (Hong et al. 2004). Therefore, emphasis of this study is placed on assessing its ability to capture the climatological structure of precipitation with respect to the diurnal cycle and regional terrain features in the complex terrain region encompassing the SMO in western Mexico. The objectives of this work include 1) qualitative and quantitative assessment of PERSIANN-CCS precipitation estimates with respect to ground-based rain gauge observations and 2) development of processbased hypothesis to explain for diagnosed bias structures, which may lead to future enhancement of the PERSIANN-CCS precipitation retrieval algorithm. Section 2 provides a more detailed description of the PERSIANN-CCS and NERN datasets as used in this validation study. Section 3 presents the principal comparisons using a suite of analyses broadly similar to those of Gochis et al. (2004). Section 4 presents a summary of the study's findings as well as some suggestions for further improvement to the precipitation observing network in the NAM region.

\section{Data and comparison}

\section{a. NERN data}

The NERN presently consists of 87 tipping-bucket recording rain gauges installed in the core North American monsoon region of northwestern Mexico, between $23^{\circ}$ and $30^{\circ} \mathrm{N}$ latitude and between $104^{\circ}$ and $111^{\circ} \mathrm{W}$ longitude (see Fig. 1). The network was designed and implemented to improve sampling of precipitation at higher elevations in the SMO, as well as provide critical event data for characterizing the diurnal cycle (Gochis et al. 2003). Gauges were installed in a 2-yr period between 2002 and 2004 and are currently being maintained indefinitely.

Since tipping-bucket rain gauges are prone to significant sources of error, careful screening of the data is required to remove gauges that have been contaminated by natural and human-induced disturbances (Steiner et al. 1999). Quality control documentation for NERN, which details the screening process and identification of problem gauges, is an ongoing component of the network operation and all suspect quality gauges have been flagged and removed from this analysis. Gochis et al. (2007) detail a rate-dependent calibration procedure used to account for "time-to-tip" errors, or the undercatch of heavy rainfall events that occurs with tipping-bucket rain gauges due to spillage of collected precipitation while the tipping bucket is in motion. The magnitude of the rate-dependent correction scales to become negligible for 5-min rainfall rates less than $25.4 \mathrm{~mm} \mathrm{~h}^{-1}$. 


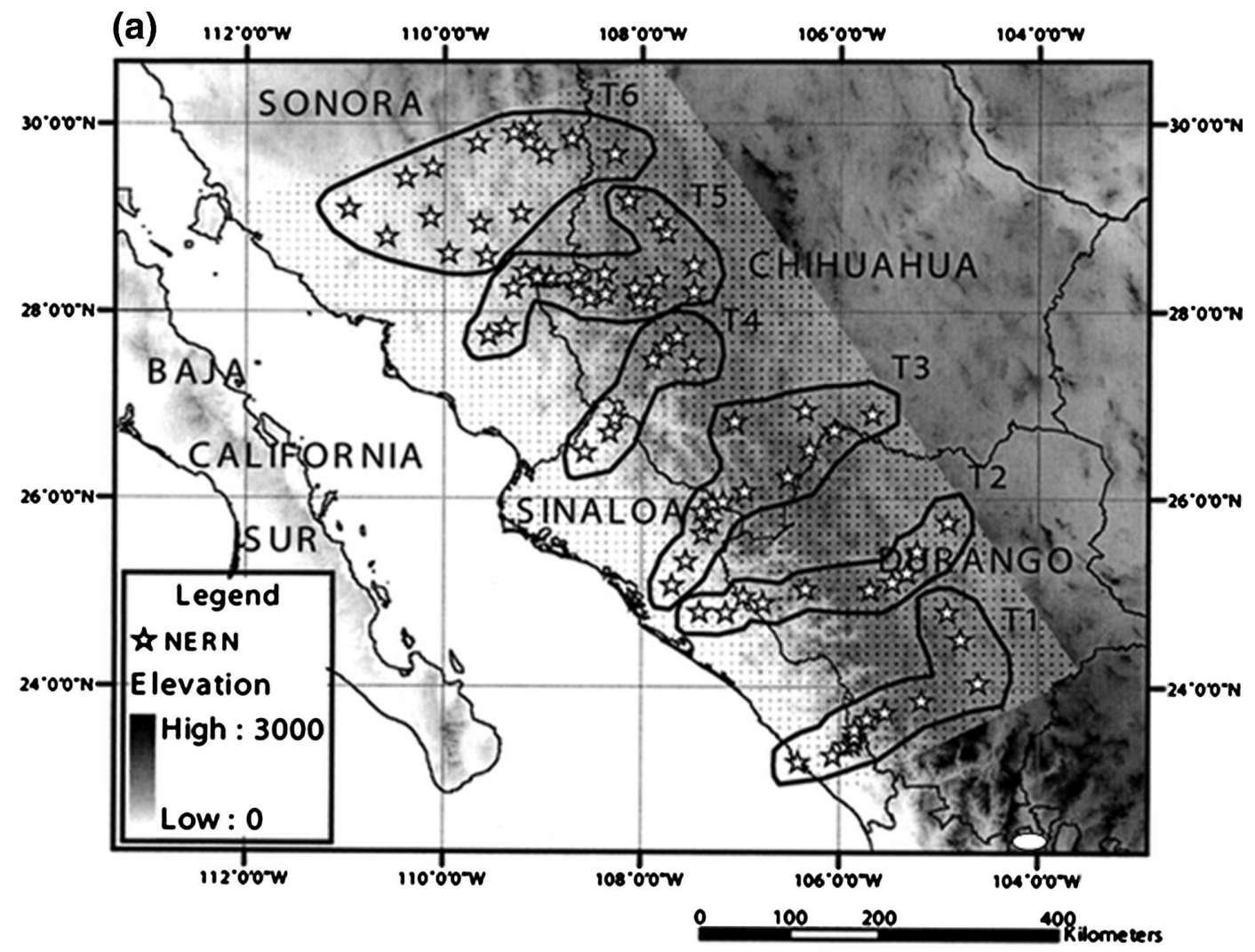

(b)

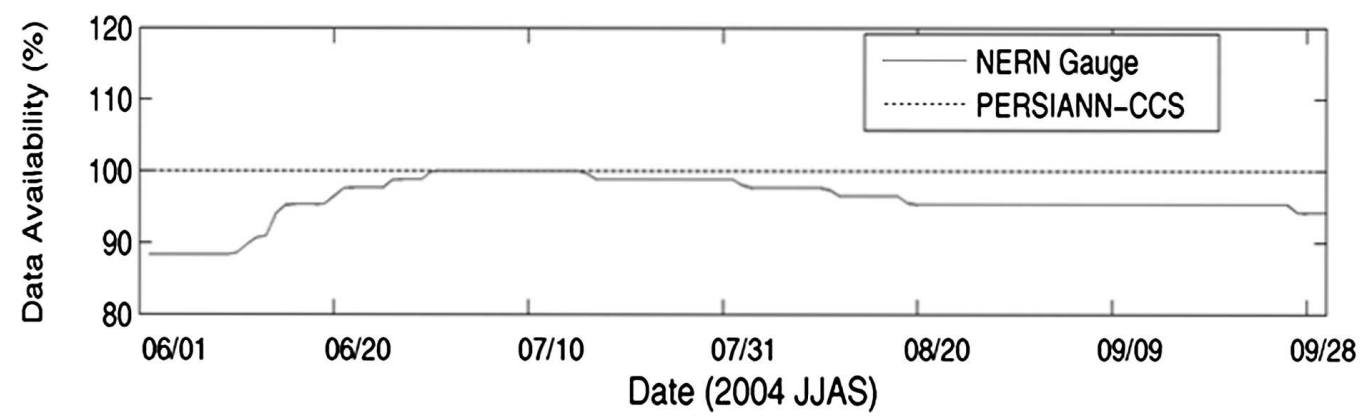

FIG. 1. (a) Map of northwestern Mexico, the NERN station locations (stars), topography (m; shaded), the NERN topographic domain (stippled), and the six transects (T1-T6). Please refer to Gochis et al. (2004) for more information; (b) hourly rainfall data availability for 2004 summer monsoon season.

Wetting losses and wind blockage and eddy effects also tend to produce systematic low biases, on the order of $2 \%-10 \%$, in rain gauge precipitation estimates (Nespor and Sevruk 1999). This bias increases with increasing wind speed and for smaller drop sizes. The NERN gauges are unshielded and, therefore, the gauge observations are potentially adversely impacted by eddy effects. However, the remotely sensed bias structures detailed below indicate that low-elevation, moderate-to-heavy precipitation (i.e., those events with a potentially smaller bias) is overestimated and high- elevation, light precipitation (i.e., those events with a larger low bias) is underestimated by the PERSIANNCCS, a relationship that would not be altered significantly if wetting loss and eddy effect biases were taken into account. Furthermore, several of the comparisons below focus on the timing of the occurrence of rainfall, not on the amount, and are thus relatively less impacted by wetting losses and eddy effects. Since no ancillary measurements of wind speed or drop size distribution were available at rain gauge sites, no attempt was made to account for wind effects in this study. 


\section{b. PERSIANN-CCS data}

NERN gauge rainfall measurements were used to evaluate the satellite-based PERSIANN-CCS rainfall estimates at a range of temporal and spatial scales. The PERSIANN-CCS algorithm extracts local and regional cloud features from infrared $(10.7 \mathrm{~mm})$ geostationary satellite imagery in estimating finer scale $\left(0.04^{\circ} \times 0.04^{\circ}\right.$ and $30 \mathrm{~min}$ ) rainfall distribution. Satellite cloud images are processed into pixel rain rates by 1) separating cloud images into distinctive cloud patches; 2) extracting cloud features, including temperature, geometry, and texture; 3) clustering cloud patches into wellorganized subgroups; and 4) calibrating cloud-top brightness temperature $\left(T_{b}\right)$ and rainfall $(R)$ relationships (i.e., $T_{b}-R$ ) for the classified cloud groups using gauge-corrected radar hourly rainfall data. Several cloud-patch categories with unique cloud-patch features and $T_{b}-R$ curves were identified and explained by Hong et al. 2004. Instead of calibrating only one $T_{b}-R$ function for all clouds the PERSIANN-CCS classifies varied cloud patches into different clusters and then searches a nonlinear best-mapping function for each cluster. This feature enables PERSIANN-CCS to generate various rain rates at a given brightness temperature and variable rain/no-rain IR thresholds for different cloud types, which overcomes the one-to-one mapping limitation of a single statistical $T_{b}-R$ function for the full spectrum of cloud-rainfall conditions. Additionally, an automated neural network for cloudpatch-based rainfall estimation, entitled Self-Organizing Nonlinear Output (SONO) model (Hong et al. 2005a), was developed to adjust the $T_{b}-R$ mapping function by using passive microwave precipitation estimates from low earth-orbiting satellite platforms, such as Tropical Rainfall Measuring Mission (TRMM) and Defense Meteorological Satellite Program. Real-time data from the current version of PERSIANN-CCS are available online (http://hydis8.eng.uci.edu/CCS/).

Several complicating factors exist when attempting to relate remotely sensed QPEs from satellites to groundbased gauge observations. One significant problem is that point measurements from gauges are not representative of the spatially averaged rainfall of a satellite field-of-view area. The footprint of each PERSIANNCCS pixel is $\sim 4 \mathrm{~km} \times 4 \mathrm{~km}$ over where the estimated surface rain rate is averaged, while the collector diameter (screened orifice) of NERN rain gauge is only 203 $\mathrm{mm}$ wide. Finescale variability of precipitation, especially convective precipitation, introduces uncertainty into estimates of spatially averaged precipitation, which cannot be accounted for by a sparse observing network, such as the NERN. Finally, as mentioned in section 2a, tipping-bucket rain gauges also suffer from additional problems, such as wetting losses, wind blockage and eddy effects, and insufficient spatial sampling of the rain gauge network (cf. Duchon and Essenberg 2001). Errors related to insufficient spatial sampling are difficult to quantify and remove without additional measurements and therefore are not dealt with here.

While the present study does not specifically address these sources of error, it is acknowledged that they potentially add uncertainty to the validation results. We also do not attempt to quantify uncertainty in the satellite-retrieved estimates related to spatial and temporal sampling of the space-borne instruments (cf. Bell and Kundu 2000; Steiner et al. 2003). Given the fine spatial resolution $(4 \mathrm{~km})$ and high temporal resolution (30 min) of the PERSIANN-CCS estimates compared to the regional (order of tens of $\mathrm{km}$ ) and seasonal time scales of the analyses, these uncertainties should be comparatively small. More specifically, the aim of this study is not to precisely quantify the error structures of the precipitation estimates from individual storm events but rather to intercompare the seasonal frequency and intensity structure of monsoon precipitation and its relationship to regional topography in northwestern Mexico between the PERSIANN-CCS and the NERN. As such, we are predominantly concerned with identifying systematic biases in the gauge observations and satellite retrieval process. For example, one well-known systematic error that we will address is that of IR-based satellite retrieval methods, which suffer from errors in brightness temperatureestimated rain rates for smaller rain rates associated with drizzle and very light precipitation.

\section{Data comparison}

In this study, NERN gauge rainfall measurements were used to evaluate the PERSIANN-CCS rainfall estimates at a range of temporal (hourly and daily) and spatial $\left(0.04^{\circ}\right)$ scales. Only PERSIANN-CCS grids with more than one rain gauge station were used for the direct comparison. Figure 1a shows the NERN gauge network and Fig. 1b shows the availability of hourly rainfall observed from the NERN gauge and PERSIANN-CCS as a function of time. Data availability through the 2004 monsoon season is estimated to be approximately $96 \%$ for NERN gauge network while the availability of PERSIANN-CCS is $100 \%$. The NERN gauge network starts to record data from June with approximately $90 \%$ coverage and increases to almost complete coverage during July-August before slowly decreasing in September. 
(a)
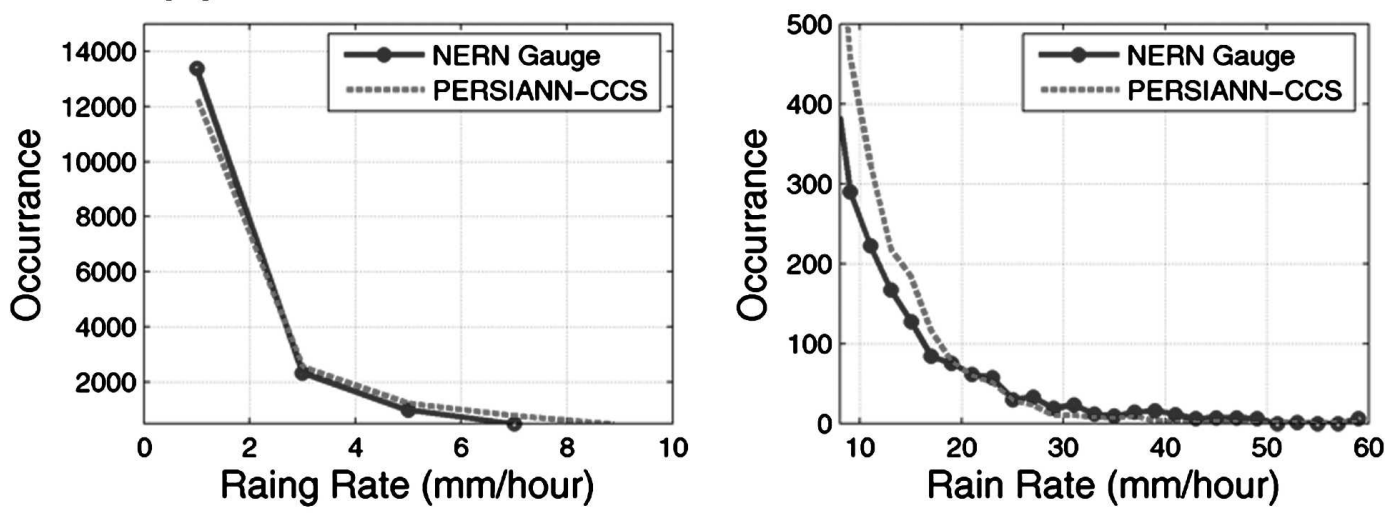

(b)

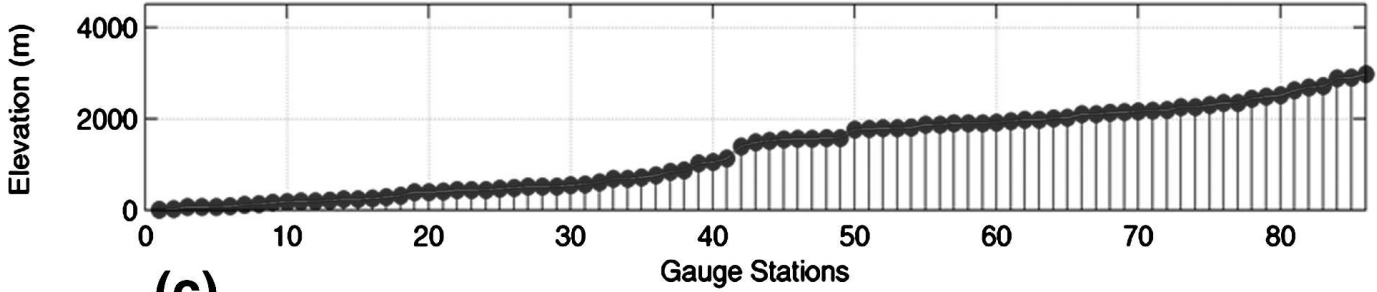

(c)

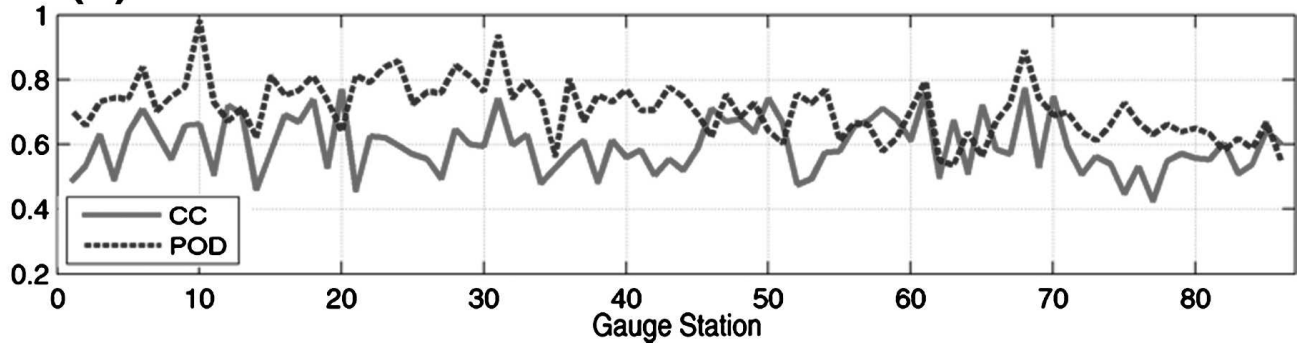

FIG. 2. Comparison of PERSIANN-CCS vs NERN gauge-estimated hourly precipitation: (a) histogram at $2 \mathrm{~mm}$ per interval; (b) 86 gauge stations reordered according to the elevation (m); and (c) the correlation coefficient (CC) and Critical Successful Index (CSI) as a function of elevation. Note that comparison is computed at hourly time scale. Therefore, each comparison point at (b), (c) has a maximum $122 \times 24$ samples.

\section{a. Comparison of hourly rain rates}

Histograms of NERN and PERSIANN-CCS hourly precipitation rates of nonzero (i.e., "wet day") precipitation are provided in Fig. 2. Both populations follow an approximate exponential distribution, where low value precipitation events are far more frequent than large events. From Fig. 2a, the PERSIANN-CCS underestimates the occurrence of very light precipitation $\left(<2 \mathrm{~mm} \mathrm{~h}^{-1}\right)$ while it tends to overestimate the occurrence of events between 2 and $20 \mathrm{~mm} \mathrm{~h}^{-1}$. The overestimate across this range contributes to a slightly positive network mean bias and positive PERSIANNCCS:NERN total precipitation ratio shown in Table 1. Figure $2 b$ shows the 86 NERN gauge stations reordered according to their elevation, while Fig. $2 \mathrm{c}$ plots the cor- relation coefficient (CC) and probability of detection (POD) of hourly rainfall estimates for each of the reordered stations. Correlation scores in Fig. 2c are largely invariant with respect to elevation. The POD, however, does exhibit a weak elevational dependence, trending toward lower values as elevation increases.

\section{b. Evaluation of daily precipitation as function of elevation}

Figure 3 shows that the PERSIANN-CCS generally has a high bias in the daily maximum and conditional daily mean rain rates at elevations lower than approximately $1500 \mathrm{~m}$, which is highlighted in the conditional mean estimate from the PERSIANN-CCS due to the removal of multiple zero precipitation days. Besides a 
TABLE 1. Network mean statistics of PERSIANN-CCS (P) vs Gauge (G) hourly estimates for all gauge stations.

\begin{tabular}{|c|c|c|c|c|c|c|c|c|}
\hline \multirow[b]{2}{*}{ Samples } & \multirow[b]{2}{*}{$\operatorname{RMSE}\left(\mathrm{mm} \mathrm{h}^{-1}\right)$} & \multirow[b]{2}{*}{$\mathrm{CC}$} & \multirow[b]{2}{*}{ POD } & \multirow{2}{*}{$\begin{array}{c}\text { Ratio } \\
\mathrm{P} / \mathrm{G}\end{array}$} & \multicolumn{2}{|c|}{ Mean } & \multicolumn{2}{|c|}{ Conditional mean } \\
\hline & & & & & $\overline{P\left(\mathrm{~mm} \mathrm{~h}^{-1}\right)}$ & $\overline{\mathrm{G}\left(\mathrm{mm} \mathrm{h}^{-1}\right)}$ & $\mathrm{P}\left(\mathrm{mm} \mathrm{h}^{-1}\right)$ & $\mathrm{G}\left(\mathrm{mm} \mathrm{h}^{-1}\right)$ \\
\hline 242222 & 1.25 & 0.58 & 0.70 & 1.05 & 0.19 & 0.18 & 3.48 & 2.41 \\
\hline
\end{tabular}

very slight underestimation of the daily mean rain rates by the PERSIANN-CCS at the highest six-seven stations, there does not appear to be such a systematic bias at the rest of the sites. Over the entire network the PERSIANN-CCS shows only a slight positive bias in daily precipitation whose RMSE, on a given day, is on the order of 2-3 mm (Table 2).

The network mean correlation for daily precipitation (0.80) provided in Table 2 is substantially higher than that for hourly precipitation (0.58) given in Table 1.
Gochis et al. (2007) showed that, while the monsoon region of northwestern Mexico is typified by heavy diurnal convection, light-to-moderate precipitation events are far more common than heavy events, particularly at higher elevations. Figures $4 b, c$ show a clear tendency for the PERSIANN-CCS to underestimate the occurrence of precipitation at lower thresholds, which is most noticeable at higher elevations. While no such systematic bias is found for moderate precipitation events in Fig. 4d, the PERSIANN-CCS generally over-

(a)
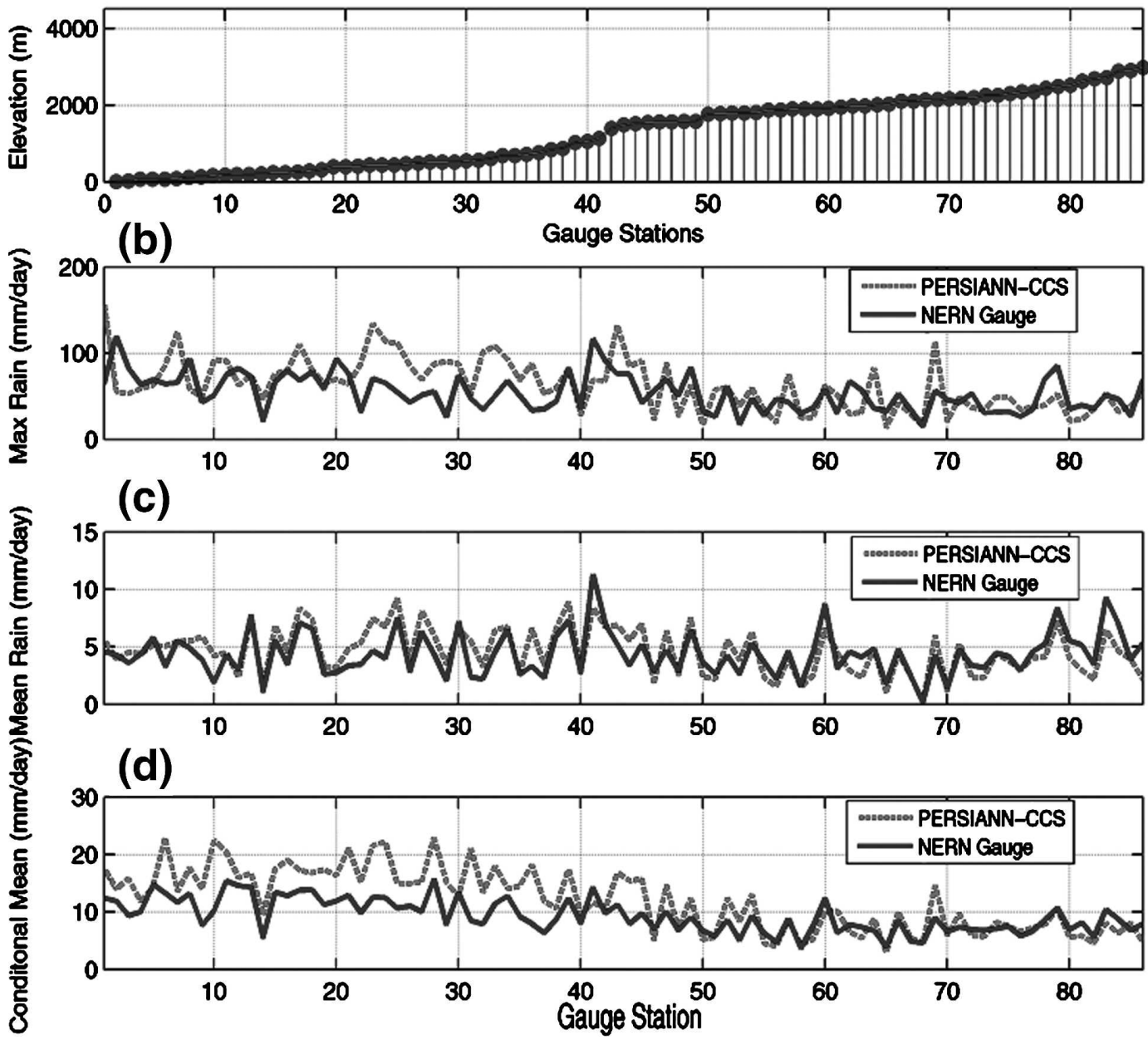

FIG. 3. Comparison of PERSIANN-CCS (P) vs NERN gauge (G) estimated daily precipitation: (a) same as in Fig. 2a; and (b)-(d) the maximum, mean, and conditional mean of 2004 summer (JJAS) daily rainfall as a function of elevation. Daily rates in (b)-(d) are in $\mathrm{mm} \mathrm{day}^{-1}$. 
TABLE 2. Statistics of daily rainfall comparison (averaged over available stations for 122 days).

\begin{tabular}{|c|c|c|c|c|c|c|c|c|c|c|c|}
\hline \multirow[b]{2}{*}{ Samples } & \multirow{2}{*}{$\begin{array}{c}\text { RMSE } \\
\left(\mathrm{mm} \mathrm{day}^{-1}\right)\end{array}$} & \multirow[b]{2}{*}{$\mathrm{CC}$} & \multirow{2}{*}{$\begin{array}{c}\text { Bias } \\
\left(\mathrm{mm} \mathrm{day}^{-1}\right)\end{array}$} & \multirow[b]{2}{*}{ POD } & \multirow{2}{*}{$\frac{\text { Ratio }}{\mathrm{P} / \mathrm{G}}$} & \multicolumn{2}{|c|}{ Mean $\left(\mathrm{mm} \mathrm{day}{ }^{-1}\right)$} & \multicolumn{2}{|c|}{ Conditional mean $\left(\mathrm{mm} \mathrm{day}^{-1}\right)$} & \multicolumn{2}{|c|}{$\operatorname{Max}\left(\mathrm{mm} \mathrm{day}^{-1}\right)$} \\
\hline & & & & & & $\mathrm{P}$ & $\bar{G}$ & $\mathrm{P}$ & $\overline{\mathrm{G}}$ & $\mathrm{P}$ & $\mathrm{G}$ \\
\hline $122 \times 86$ & 2.85 & 0.80 & 0.19 & 0.98 & 1.04 & 4.56 & 4.37 & 4.72 & 4.45 & 28.52 & 21.25 \\
\hline
\end{tabular}

estimates the occurrence of heavy precipitation events, particularly at lower elevation sites. Table 3 shows similar tendencies in the network mean probabilities as functions of rainfall rate thresholds. From the magni- tude of the probabilities plotted in Fig. 4e, heavy events, as defined here, are comparatively rare. This means that sample sizes or the number of cases to verify from a single season are likely to be small [on the order
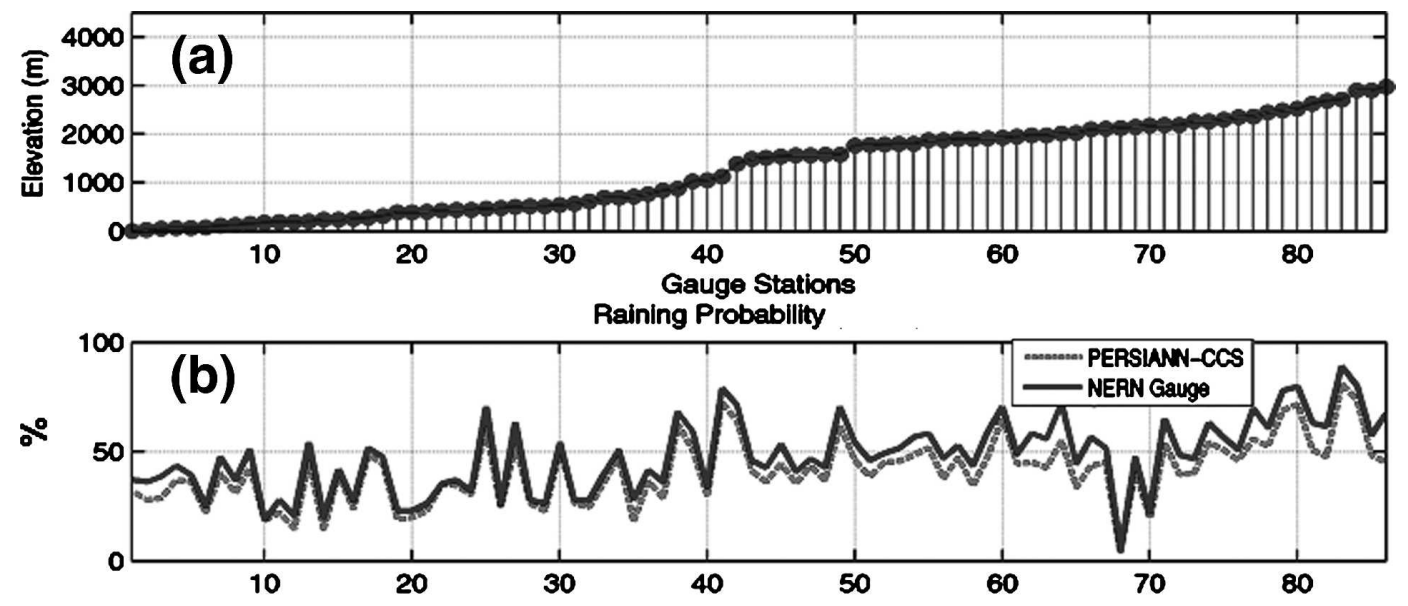

Light Rain (0-10mm/day)

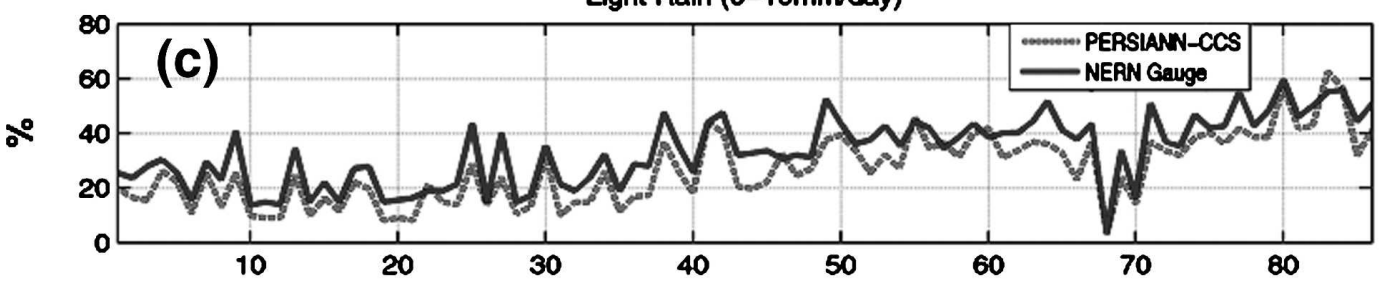

Moderate Rain (10-50.8mm/day)
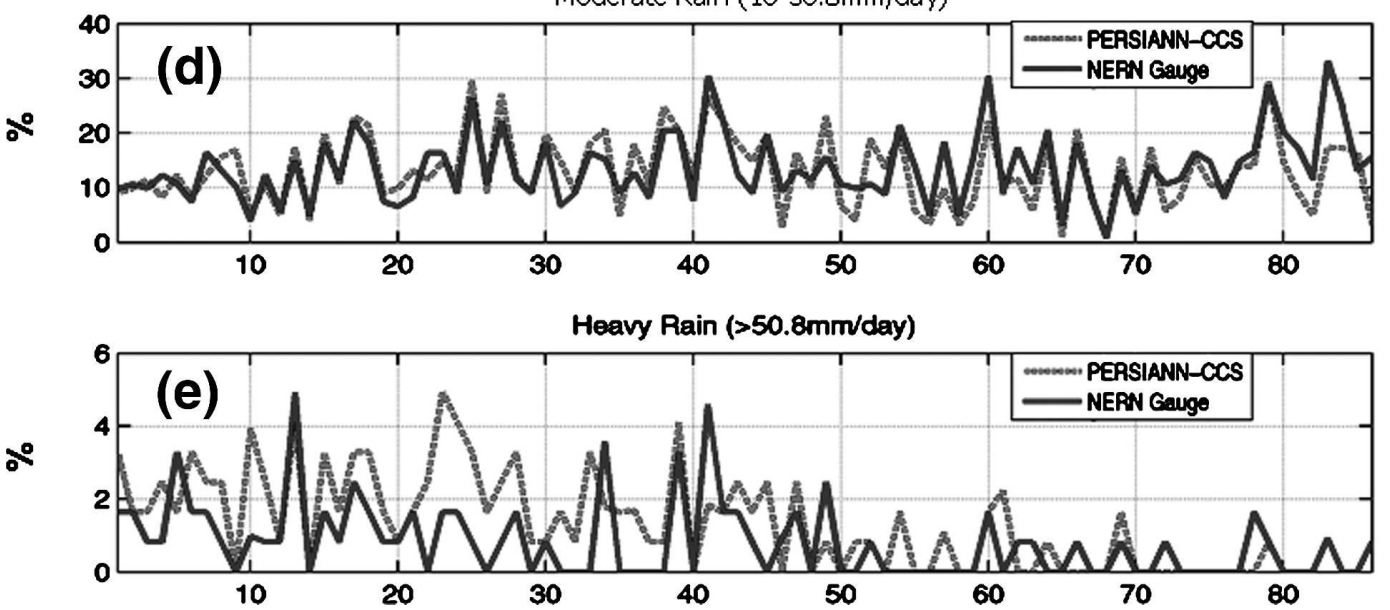

FIG. 4. (a) Same as in Fig. 3a; (b)-(e) probability of raining days, light rainfall (0-10 $\left.\mathrm{mm} \mathrm{day}^{-1}\right)$, moderate rainfall $\left(10-50.8 \mathrm{~mm} \mathrm{day}^{-1}\right)$, and heavy rainfall $\left(>50.8 \mathrm{~mm} \mathrm{day}^{-1}\right)$ over the 2004 summer (JJAS) as a function of elevation. Note that the statistics are computed at daily time scales for each gauge station, which is reordered according to its elevation. 
TABLE 3. Estimated probabilities of daily rainfall average of all stations (heavy, moderate, light rainfall, or occurrence of any rainfall).

\begin{tabular}{|c|c|c|c|c|c|c|c|c|}
\hline \multirow[b]{2}{*}{ Samples } & \multicolumn{2}{|c|}{ Light rain (\%) } & \multicolumn{2}{|c|}{ Moderate rain $(\%)$} & \multicolumn{2}{|c|}{ Heavy rain $(\%)$} & \multicolumn{2}{|c|}{ Rain probability (\%) } \\
\hline & $P$ & G & $\mathrm{P}$ & G & $\mathrm{P}$ & G & $\mathrm{P}$ & G \\
\hline 10087 & 26.65 & 33.27 & 13.05 & 13.57 & 1.31 & 0.79 & 48.151 & 56.023 \\
\hline
\end{tabular}

of 0-4 for an individual site according to Gochis et al. (2007)] and therefore these bias estimates possess a large degree of uncertainty. Nevertheless, the transition from a slight but systematic underestimate of light rain events at high elevations to an overestimate of large threshold events at low elevations indicates that the PERSIANN-CCS does have some difficulty in reproducing certain aspects of the climatological spatial distribution of the precipitation intensity-frequency relationship.

\section{c. Evaluation at daily scale as function of latitude}

The NERN stations were rearranged in order of increasing latitude (northward) and their daily rain- fall amounts are plotted according to time and latitude ( $x$ and $y$, respectively) in Fig. 5. Figure 5 shows intermittent active periods at the beginning of monsoon season during June. The active period near 20 June exhibits a phase shift of approximately 2-4 days proceeding northward. While this event was not characterized in operational reports as a classic "moisture surge" event (cf. Stensrud et al. 1997; Douglas and Leal 2003; or Higgins et al. 2004) it was tied to a slow-moving, largescale incursion of tropical moisture from farther south (NAME 2004 field campaign daily summaries available online at http://www.cpc.ncep.noaa.gov/products/ precip/monsoon/). A second instance exhibiting a lati-

(a)

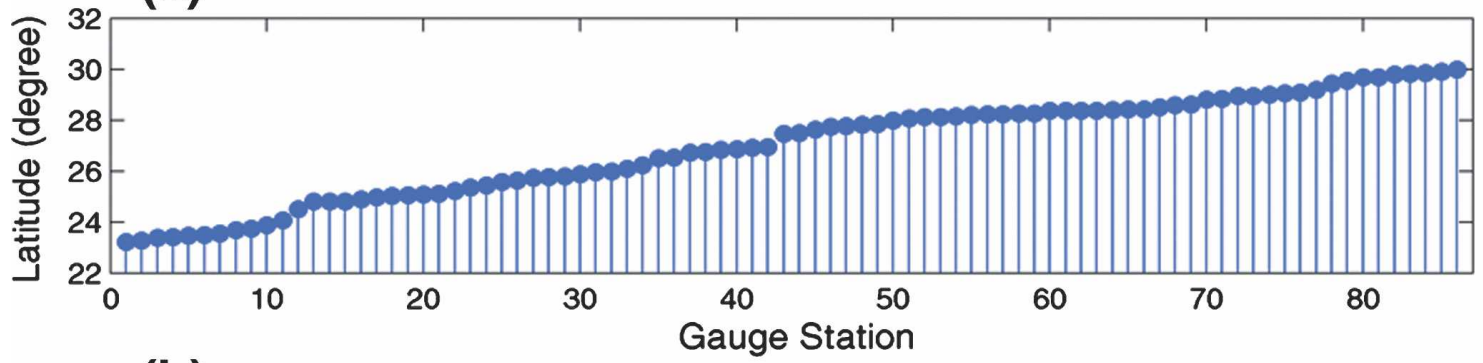

(b)

PERSIANN-CCS

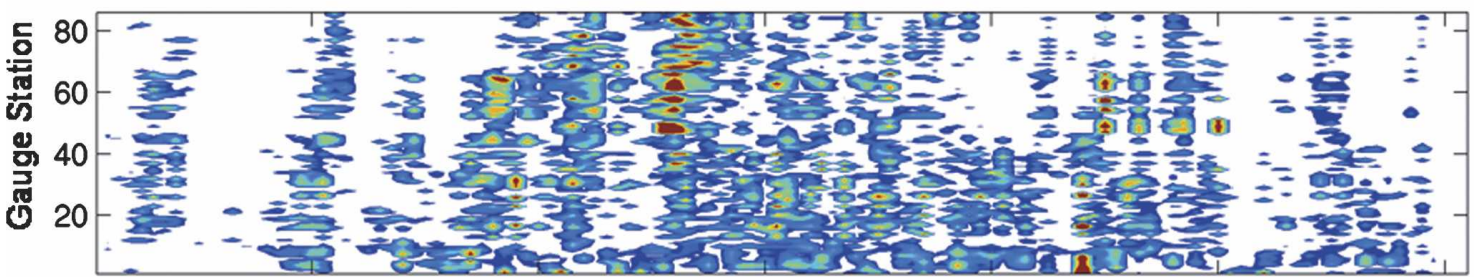

(c)

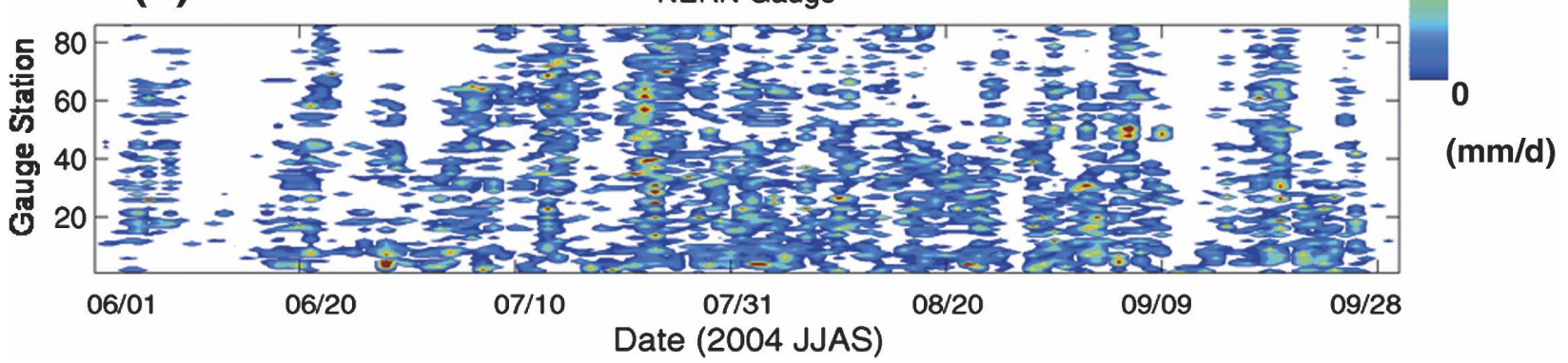

FIG. 5. (a) The 86 gauge stations reordered according to their latitude; (b), (c) the surging of monsoon observed from PERSIANNCCS and NERN gauge over the 2004 summer (JJAS). Note that the statistics are computed at daily rainfall time scales for each gauge station, which were reordered according to their latitude. 
tudinal progression of precipitation occurs on 12-14 July, which was characterized as a moisture surge event associated with the passing of Tropical Storm Blas south of Baja California, Mexico. Within the NERN domain there does not appear to be an obviously large influence of latitudinally propagating systems during the mature phase of the monsoon from mid-July through mid-August when rainfall appears to be relatively widespread across all latitudes. It is worth noting that Gochis et al. (2004) found that moisture surge events defined at Guaymas, Sonora, Mexico tend to influence low-elevation stations greater than middleand high-elevation stations (a finding similar to that of Douglas and Leal 2003), and the presentation of all stations in Fig. 5 may mask such an elevation-specific response. It is also evident that the PERSIANN-CCS slightly underdetects rainfall during the latter portion of the monsoon season in September, which we hypothesize may be attributed to an underestimation of comparatively warm shallow convection.

\section{d. Diurnal cycle of precipitation}

Figure 6 provides a direct comparison of the 2004 diurnal cycle of precipitation from the PERSIANNCCS and the NERN using the diagnostics developed within Gochis et al. (2004). Although Hong et al. (2005b) demonstrated that representation of diurnal variability was improved by adjusting satellite IR-based rainfall estimates with passive microwave sensors, the PERSIANN-CCS still shows 1-2-h phase offset in Fig. $6 a$. The phase offset is correlated to the elevation-dependent biases shown earlier in Figs. 3 and 4. Gochis et al. (2004) found that precipitation initiated earliest at the higher elevations of the SMO and tended to propagate both westward and eastward away from the cordillera into the evening hours. Precipitation at the lowest elevations and in the far northern transect of the NERN domain, often occurred late at night or in the early morning hours. The underestimate of the PERSIANN-CCS estimated rain rates in the early afternoon shown here are attributable to the low bias in precipitation at high elevations of the SMO. By early evening and nighttime the PERSIANN-CCS is overestimating hourly rain rates, which, from Figs. 3-4, are attributed to a high bias at low elevations. Figures $6 \mathrm{~b}, \mathrm{c}$, which show the diurnal cycle of rain rates for $500-\mathrm{m}$ elevation bands, confirm this behavior. It is clear that the PERSIANN-CCS is underestimating the early afternoon rainfall in the highest elevation band (2500$3000 \mathrm{~m}$ ) and is largely overestimating rainfall in the 0-500-, 500-1000-, and 1000-1500-m bands during the evening and nighttime.
The transect-averaged diurnal cycles in Figs. 6d,e (note NERN transects are defined in Fig. 1a) also show evidence of the phase-dependent biases in the PERSIANN-CCS. The amplitudes of all transects, except transect 6 (northernmost transect), are greater in the PERSIANN-CCS data estimates than in the NERN data. These narrow but more peaked curves across transects agree with delayed early afternoon rainfall and enhanced evening-nighttime rainfall. Transect 6 , as noted by Gochis et al. (2004), behaves somewhat differently than the other five transects farther south. Based on the results shown here it appears as though the PERSIANN-CCS does a reasonably good job in estimating the diurnal cycle of rain rates in this northern region compared to the other transects.

The intraseasonal evolution of the network average diurnal cycle of precipitation from its intermittent beginnings in June through its mature phase is clearly evident in Fig. 7. Figure 7 indicates the largest daily rainfall event occurred in late July (24th) in both the PERSIANN-CCS and NERN datasets. This event is also elaborated upon in Gochis et al. (2007). While the PERSIANN-CCS appears to capture the dominant behavior of the monsoon in its early and mature phases, it fails to adequately capture several late season (or "senescent period") events between 14 and 23 September. Figures 7b,c also allow for intercomparison of the evolution of rainfall diurnal variability during the monsoon season. At the beginning and ending of the season, the rainfall occurs mostly between the evening (1800 LT) and early morning (0300 LT) hours. As shown in Fig. 6, the onset of rains in the afternoon in the PERSIANNCCS lags behind that of the NERN by $1-2 \mathrm{~h}$. During the mature phase of the monsoon season (i.e., late July through mid-August), precipitation in both the NERN and PERSIANN-CCS initiates earlier in the day, between 1200 and 1400 LT. The magnitude of the precipitation events, from a network average standpoint, also tends to be greatest during the mature phase in late July.

Figure 8 clearly shows the evolution of the diurnal cycle of precipitation from high (mountain) to low elevation (coast) regions. Precipitation over mountain regions generally occurs early afternoon, around 1200 LT, and ends around midnight. The diurnal cycle of precipitation over coastal regions initiates 2-4 h later and extends well into the morning hours. Although the PERSIANN-CCS captures this principal behavior of the diurnal cycle, the bias structure described above and evident in Fig. 8 as a phase shift in the afternoon onset and morning termination of precipitation, suggests the diurnal cycle of certain cloud characteristics important to precipitation estimation may be misrepre- 

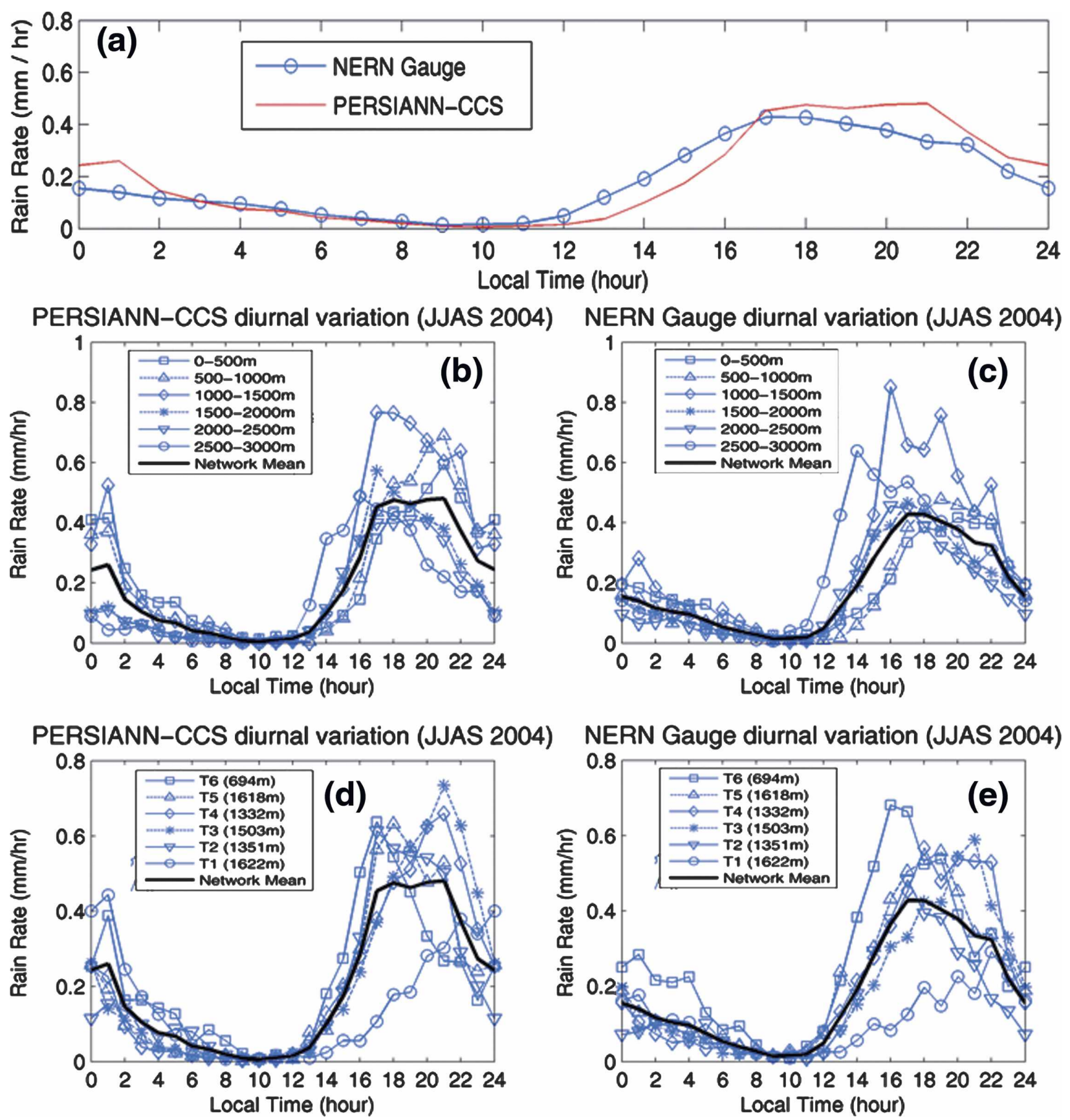

FIG. 6. Diurnal variation of rainfall observed from PERSIANN-CCS and NERN gauge over the 2004 summer (JJAS): (a) diurnal rainfall variation averaged from the 86 gauge stations and (b), (c) the diurnal variation of rainfall averaged from different elevation bands and (d), (e) from different transactions.

sented or unaccounted for. In particular, the underestimate of light precipitation both at high elevations (Fig. 4) and early in the day (Fig. 8) suggests that the PERSIANN-CCS may not properly represent warm rain processes associated with convective-orographic lift and shallow convection. Similarly, the pronounced positive bias in low-elevation, moderate-to-heavy pre- cipitation may also be related to improper characterization of deep convective events in which rainfall estimates can be influenced by ice-phased processes, cirrus anvil contamination, and evaporation of rainfall. A detailed investigation of cloud microphysical processes using polarimetric retrievals collected during the 2004 field campaign (cf. Lang et al. 2007) will provide sig- 
(a) 2004 Summer Daily Rainfall Time Series (JJAS)
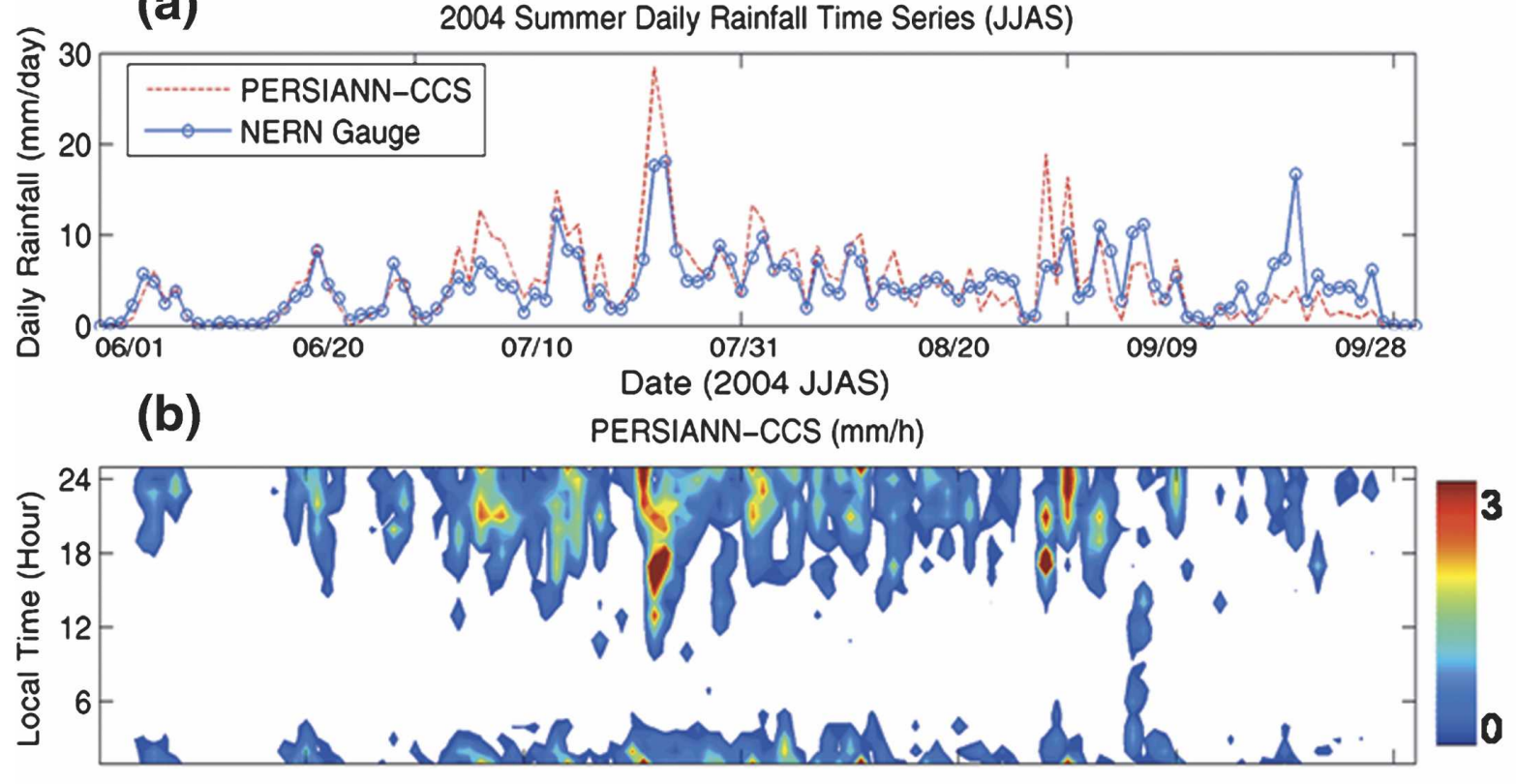

(c) NERN Gauge $(\mathrm{mm} / \mathrm{hr})$

$\mathrm{mm} / \mathrm{h}$

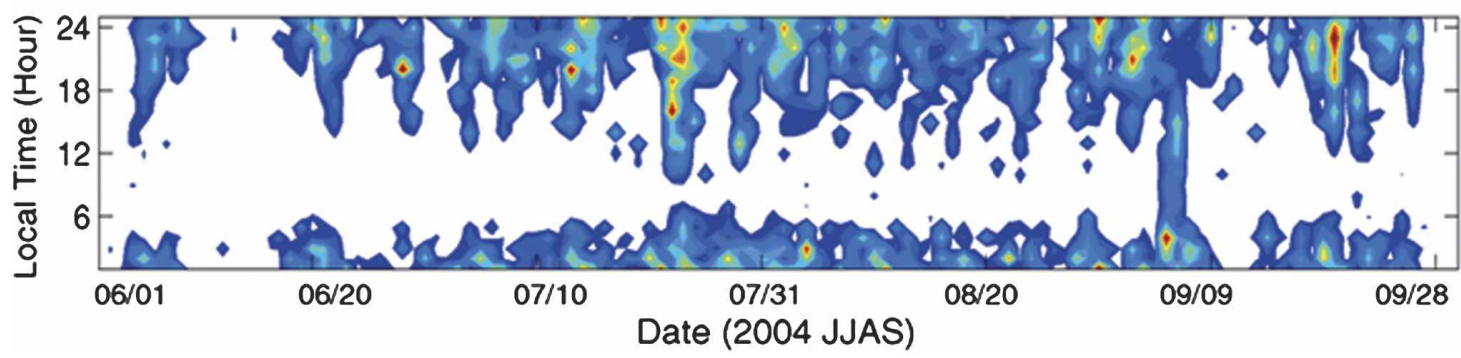

FIG. 7. (a) Time series of daily rainfall observed from PERSIANN-CCS estimates and NERN gauge rainfall at network domain average; (b), (c) the evolution of rainfall diurnal variation as a function of time over the 2004 summer (JJAS). Daily rate and diurnal variation averaged from whole network for each day.

nificant insight into these issues but is beyond the scope of the present study.

Our demonstration on the effects of terrain to the variation, in terms of timing and intensity, of diurnal rainfall pattern is consistent with that founded by Gochis et al. (2004, 2007). As shown in Figs. 6 and 8, the PERSIANN-CCS reasonably captures the general evolution of the diurnal cycle, originating over the high terrain of the SMO and progressively downslope to the west and east. Nocturnal precipitation structures there in both frequency and intensity are dominant along the coast of the Gulf of California. The PERSIANNCCS characterizes most of the Gulf of California, portions of the low-elevation deserts in southern Arizona, and the region at the mouth of the Colorado River in northern Sonora as a nocturnally dominated regime (not shown).

\section{Summary and conclusions}

The NERN has been proved to be highly valuable for investigation of North American monsoon precipitation characteristics (Gochis et al. 2004, 2007). It also provides a research-quality gauge rainfall dataset to evaluate satellite-based precipitation estimates. However, given the spatial limitation of gauge measurements, satellite-based precipitation estimates, once confidently validated, could significantly contribute to improved understanding of monsoon precipitation in complex terrain regions. This study provides quantitative assessment of PERSIANN-CCS quantitative precipitation estimates (QPEs) against NERN gauge observations.

Direct intercomparison of NERN gauge observations and PERSIANN-CCS precipitation estimates from the 
(a)

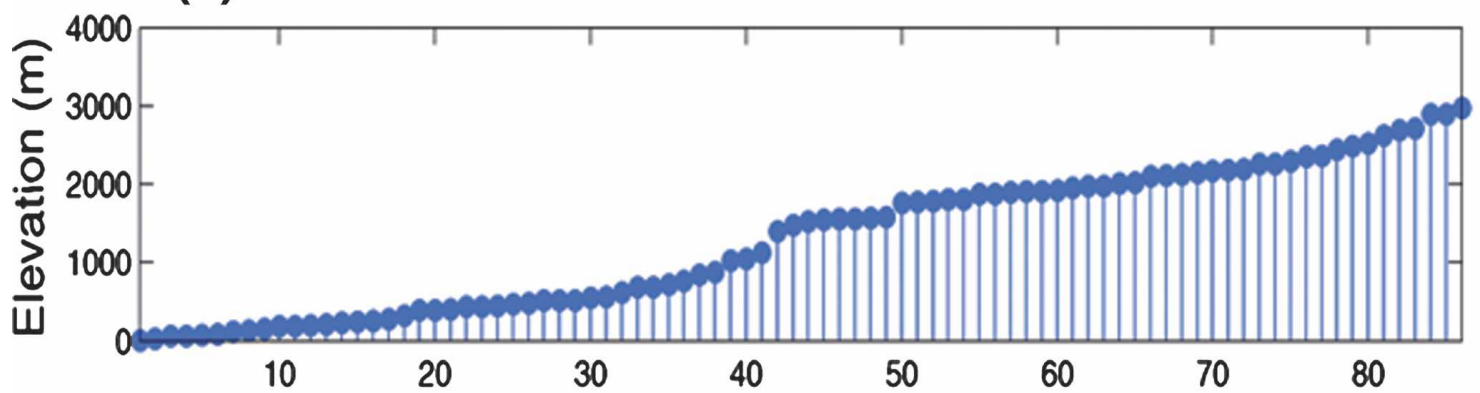

(b) PERSIANN-CCS

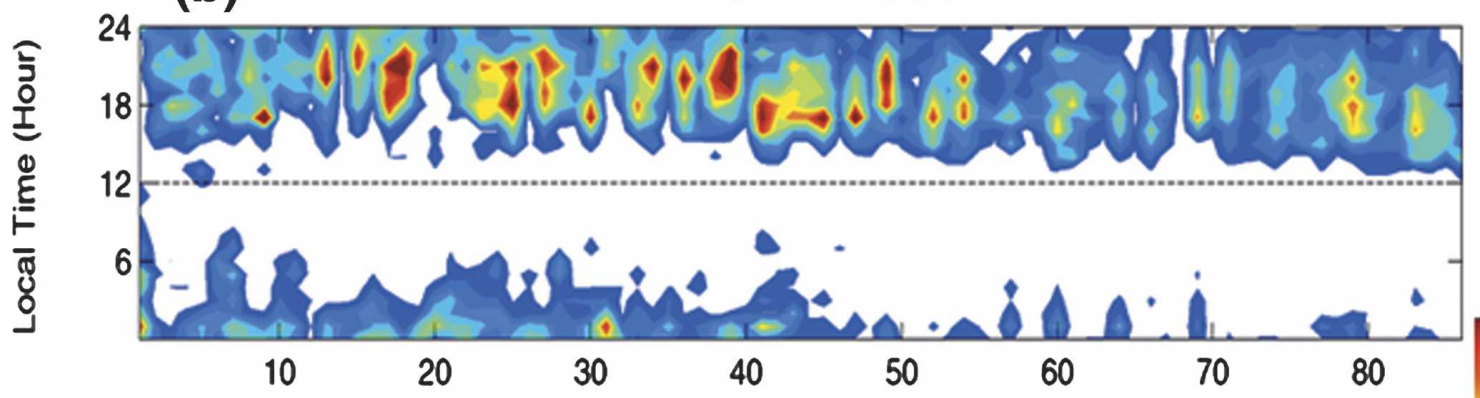

(c)

NERN Gauge

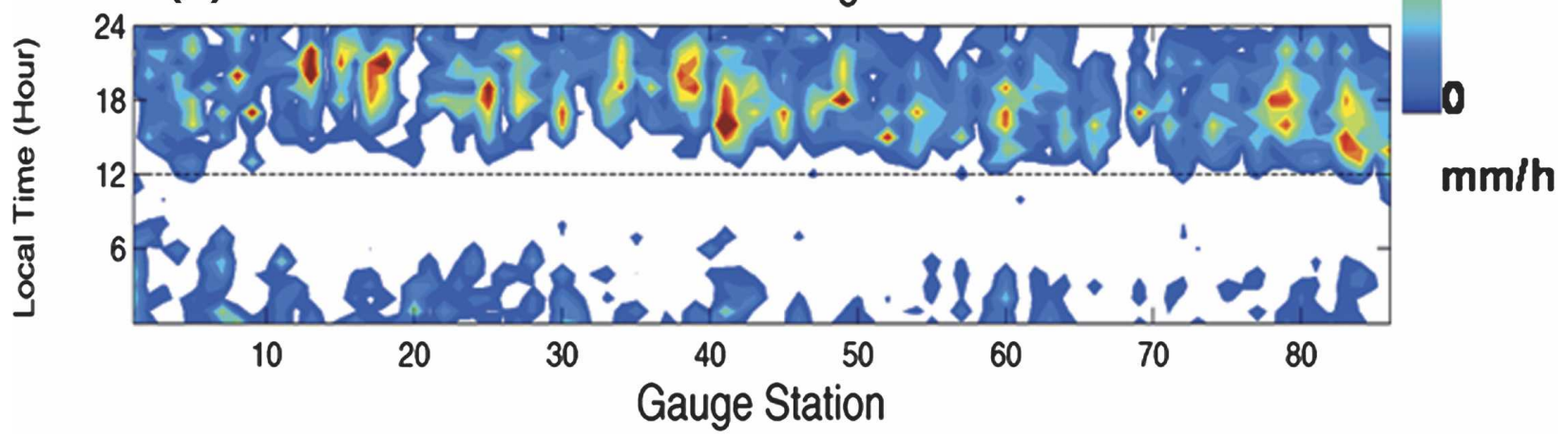

FIG. 8. (a) Same as in Fig. 4a; comparison of the diurnal cycle of precipitation rate (shown in color) as it varies with elevation between (b) the PERSIANN-CCS and (c) the NERN.

summer of 2004 [June-September (JJAS)] shows that spatial and temporal rainfall characteristics over the NAM region are generally well captured by the PERSIANN-CCS estimates. However, some systematic bias structures exist that need to be addressed in future upgrades to the PERSIANN-CCS estimation algorithm. The principal findings from this validation study are summarized as follows.

- Elevation-dependent biases exist in PERSIANNCCS QPEs that are characterized by an underestimate in the occurrence of light precipitation at high elevations and an overestimate in the occurrence of precipitation at low elevations.
- The elevation-dependent bias structures in the PERSIANN-CCS result in a small positive network average bias at both hourly and daily time scales.

- The elevation-dependent biases contribute to a 1-2-h delayed phase shift of the diurnal cycle of precipitation at various elevation bands.

- The PERSIANN-CCS reasonably depicts active and break periods in the early and mature phases of the monsoon season. Time-latitude plots of daily precipitation from the PERSIANN-CCS also exhibit latitudinal propagation structures broadly similar to those of moisture surge events.

- The PERSIANN-CCS, for reasons yet to be determined, failed to capture a few active periods of pre- 
cipitation during the late or "senescent" phase of the monsoon.

More generally, PERSIANN-CCS QPEs are in agreement with earlier NERN studies, which characterize the NAM precipitation regime in which rainy days are more frequent at higher elevations, high-intensity storms are more commonly, though not exclusively, found at lower elevations, maximum rainfall occurs earlier in the day at high elevations ( $\sim 1700$ UTC) rather than low elevations ( $\sim 2200$ UTC), and maximum seasonal rainfall occurs on the western slopes of the Sierra Madre Occidental (SMO).

Findings from this study motivate a few additional points. First, additional work is needed to develop a better understanding of the sources of the elevationdependent biases found in this verification. The bias structure suggests that the PERSIANN-CCS may have an increased sensitivity to deep convection, which generates heavy precipitation at the expense of missing lighter precipitation events. The underestimate in light precipitation events early in the day may also suggest that the PERSIANN-CCS has difficulty estimating precipitation in comparatively shallow and warm (i.e., nonice) convective clouds. The overall positive bias from remotely sensed precipitation estimates could be due, in part, to the evaporation of rain before it reaches the ground. One way to account for this overestimation is to use relative humidity data from the surface to 500 $\mathrm{hPa}$ from a numerical forecast model analysis to modify the satellite rainfall estimates (e.g., Janowiak et al. 2004). Second, more investigation into the convectiveorographic effects of precipitation processes upon satellite-based precipitation retrieval algorithm is needed. A regionally dependent empirical elevation-based bias correction technique may also help improve the quality of satellite-derived precipitation products. Third, it is not yet clear why the PERSIANN-CCS had difficulty capturing the late monsoon active period during September. More detailed examination of these events is required to determine what types of precipitating structures existed during this event and why the PERSIANN-CCS had difficulty representing it. Last, the IR-based satellite precipitation estimation generally exhibits 1-3-h phase shift with respect to the peak of diurnal rainfall (Sorooshian et al. 2002) because the cold cloud-top brightness temperature inferred from cirrus canopies may contribute to the phase delay (Hong et al. 2005b). One solution for this phase shift is to incorporate information that is able to discern the vertical structure of precipitation systems (i.e., convective versus stratiform). The existing precipitation radar in TRMM and future dual-frequency precipitation radar in planned Global Precipitation Measuring Mission could potentially enhance the ability of the PERSIANN-CCS algorithm to discern the types of precipitation structures.

High-resolution remotely sensed QPEs, such as the PERSIANN-CCS, offer great potential for studying surface hydrological processes in remote, complex terrain regions. However, these estimates must be properly validated against other reliable precipitation observation in order to verify their accuracy. Unaccounted for, biases in QPEs will propagate through hydrological modeling systems in nonlinear ways thereby degrading the model simulation and prediction capability (Hong et al. 2006). Regional precipitation observing networks such as the NERN and high-quality weather radars form important components of QPE validation efforts by providing insight into local and regional precipitation characteristics and processes. Based on the findings presented here, it is critically important that validation sites adequately sample elevation-precipitation relationships in complex terrain regions because precipitation character can vary greatly over short distances. Ancillary measurements that provide information on the diurnal cycle of temperature and humidity at different elevations would also be helpful in characterizing the subcloud environment. Once calibrated or bias corrected, satellite-based precipitation estimates, such as those from the PERSIAN-CCS, should be useful in hydrological applications.

Acknowledgments. Support for this work was provided by the NASA TRMM project (NAG5-7716) and NASA EOS project (Award NNG05GA20G), as well as the NOAA Office of Global Programs Contracts NA04OAR4310166 and NA030AR4310073. Presentation of this work was greatly enhanced by the constructive comments of three anonymous reviews.

\section{REFERENCES}

Bell, T. L., and P. K. Kundu, 2000: Dependence of satellite sampling error on monthly averaged rain rates: Comparison of simple models and recent studies. J. Climate, 13, 449-462.

Berbery, E. H., 2001: Mesoscale moisture analysis of the North American monsoon. J. Climate, 14, 121-137.

Carleton, A. M., 1986: Synoptic-dynamic character of "bursts" and "breaks" in the southwest U.S. summer precipitation singularity. J. Climatol., 6, 605-623.

Douglas, M. W., and J. C. Leal, 2003: Summertime surges over the Gulf of California: Aspects of their climatology, mean structure, and evolution from radiosonde, NCEP reanalysis, and rainfall data. Wea. Forecasting, 18, 55-74.

_, R. A. Maddox, K. Howard, and S. Reyes, 1993: The Mexican monsoon. J. Climate, 6, 1665-1677.

Duchon, C. E., and G. R. Essenberg, 2001: Comparative rainfall 
observations from pit and aboveground rain gauges with and without wind shields. Water Resour. Res., 37, 3253-3263.

Gochis, D. J., J.-C. Leal, W. J. Shuttleworth, C. J. Watts, and J. Garatuza-Payan, 2003: Preliminary diagnostics from a new event-based precipitation monitoring system in support of the North American Monsoon Experiment. J. Hydrometeor., 4, 974-981.

- A. Jimenez, C. J. Watts, J. Garatuza-Payan, and W. J. Shuttleworth, 2004: Analysis of 2002 and 2003 warm-season precipitation from the North American Monsoon Experiment event rain gauge network. Mon. Wea. Rev., 132, 29382953.

—, L. Brito-Castillo, and W. J. Shuttleworth, 2006: Hydroclimatology of the North American monsoon region in northwest Mexico. J. Hydrol., 316, 53-70.

_ C. C. J. Watts, J. Garatuza-Payan, and J. Cesar-Rodriguez, 2007: Spatial and temporal patterns of precipitation intensity as observed by the NAME event rain gauge network from 2002 to 2004. J. Climate, 20, 1734-1750.

Higgins, R. W., and Coauthors, 2003: Progress in Pan American CLIVAR Research: The North American monsoon system. Atmosfera, 16, 29-65.

— W. Whi, and C. Hain, 2004: Relationships between Gulf of California moisture surges and precipitation in the southwestern United States. J. Climate, 17, 2983-2997.

— modeling strategy. Bull. Amer. Meteor. Soc., 87, 79-94.

Hong, Y., K.-L. Hsu, S. Sorooshian, and X. Gao, 2004: Precipitation estimation from remotely sensed imagery using an artificial neural network cloud classification system. J. Appl. Meteor., 43, 1834-1853.

,,--- , and $\longrightarrow, 2005$ a: Self-organizing nonlinear output (SONO): A neural network suitable for cloud patchbased rainfall estimation at small scales. Water Resour. Res., 41, W03008, doi:10.1029/2004WR003142.

,$--\longrightarrow$, and $-2005 \mathrm{~b}$ : Improved representation of diurnal variability of rainfall retrieved from the Tropical Rainfall Measurement Mission Microwave Imager adjusted
Precipitation Estimation from Remotely Sensed Information Using Artificial Neural Networks (PERSIANN) system. $J$. Geophys. Res., 110, D06102, doi:10.1029/2004JD005301.

,,-- H. Moradhani, and S. Sorooshian, 2006: Uncertainty quantification of satellite precipitation estimation and Monte Carlo assessment of the error propagation into hydrologic response. Water Resour. Res., 42, W08421, doi:10.1029/ 2005WR004398.

Janowiak, J. E., P. Xie, R. J. Joyce, M. Chen, and Y. Yarosh, 2004: Validation of satellite-derived rainfall estimates and numerical model forecasts of precipitation over the United States. Proc. 29th Annual Climate Diagnostics and Prediction Workshop, Madison, WI, NOAA, 21-26.

Lang, T., D. Ahijevych, S. Rutledge, S. Nesbitt, R. Carbone, and R. Cifelli, 2007: Radar-observed characteristics of precipitating systems during NAME 2004. J. Climate, 20, 1713-1733.

Mosiño, P., and E. Garcia, 1974: The climate of Mexico. Climates of North America, R. A. Bryson and K. F. Hare, Eds., Vol. 11, World Survey of Climatology, Elsevier, 345-404.

Nespor, V., and B. Sevruk, 1999: Estimation of wind-induced error of rainfall gauge measurements using a numerical simulation. J. Atmos. Oceanic Technol., 16, 450-464.

Sorooshian, S., X. Gao, K. Hsu, R. A. Maddox, Y. Hong, H. V. Gupta, and B. Imam, 2002: Diurnal variability of tropical rainfall retrieved from combined GOES and TRMM satellite information. J. Climate, 15, 983-1001.

Steiner, M., J. A. Smith, S. J. Burges, C. V. Alonso, and R. W. Darden, 1999: Effect of bias adjustment and rain gauge data quality control on radar rainfall estimation. Water Resour. Res., 35, 2487-2503.

_ - T. L. Bell, Y. Zhang, and E. F. Wood, 2003: Comparison of two methods for estimating the sampling-related uncertainty of satellite rainfall averages based on a large radar dataset. $J$. Climate, 16, 3759-3778.

Stensrud, D. J., R. L. Gall, and M. K. Nordquist, 1997: Surges over the Gulf of California during the Mexican monsoon. Mon. Wea. Rev., 125, 417-437. 